\title{
Expression of Uncoupling Protein 3 and GLUT4 Gene in Skeletal Muscle of Preterm Newborns: Possible Control by AMP-Activated Protein Kinase
}

\author{
PETR BRAUNER, PAVEL KOPECKY, PAVEL FLACHS, ONDREJ KUDA, JAROSLAV VORLICEK, LENKA PLANICKOVA, \\ IVANA VITKOVA, FABRICIO ANDREELLI, MARC FORETZ, BENOIT VIOLLET, AND JAN KOPECKY
}

\begin{abstract}
Institute of Physiology [P.B., P.F., O.K, J.V., J.K.], Academy of Sciences of the Czech Republic, 14220 Prague; Department of Obstetrics and Gynecology [P.K.], Division of Neonatology, Institute of Pathology [L.P., I.V.], General Hospital of the First Medical Faculty, Charles University, 12802 Prague, Czech Republic; Department of Genetic, Developmental and Molecular Pathology [F.A., M.F., B.V.], Institut Cochin, INSERM, CNRS, Rene Descartes University, 75014 Paris, France
\end{abstract}

\begin{abstract}
We seek to understand the mechanism for the delayed postnatal switch between glycolytic and oxidative metabolism in preterm newborns. Our previous study [Brauner et al. (Pediatr Res 53: 691-697, 2003)] suggested impaired postnatal recruitment of the gene for mitochondrial uncoupling protein 3 (UCP3) by nutritional lipids in skeletal muscle of neonates delivered before approximately 26 wk of gestation. UCP3 is linked to lipid oxidation and may be involved in the defective development of energy metabolism in skeletal muscles of very preterm newborns. In extension of our previous study, autopsy samples of musculus quadriceps femoris from 40 mostly preterm neonates and 5 fetuses were used for quantification of transcripts for UCP3, GLUT4, and their transcriptional regulator, AMP-activated protein kinase (AMPK). The new analysis confirmed the defect in the recruitment of the UCP3 gene expression by lipids in very preterm neonates. It also suggested involvement of AMPK in the control of expression of both metabolic genes, UCP3 and GLUT4, in the skeletal muscle of the newborns. Experiments on adult C57BL/6J mice confirmed the relationships between the transcripts and supported the involvement of AMPK in the control of UCP3 gene expression. (Pediatr Res 60: 569-575, 2006)
\end{abstract}

\begin{abstract}
A daptation to extrauterine life depends largely on a switch from glycolytic to oxidative metabolism. Several studies (1-3) demonstrated the recruitment of energy conversion and ATP synthesis in mitochondria during the early postnatal period as well as insufficient maturation of this mechanism in premature newborns (4,5). Results of our previous study (6) on autopsy samples of skeletal muscle, mostly from preterm neonates, suggested impaired postnatal recruitment by nutritional lipids $(7,8)$ of the gene for mitochondrial uncoupling protein 3 (UCP3) in neonates delivered before approximately 26 wk of gestation. UCP3 was shown to uncouple mitochondrial oxidative phosphorylation in vivo (9); it is specifically
\end{abstract}

Received May 18, 2006; accepted June 22, 2006

Correspondence: Jan Kopecky, M.D., Ph.D., Institute of Physiology, Academy of Sciences of the Czech Republic, Videnska 1083, 14220 Prague, Czech Republic; e-mail: kopecky@biomed.cas.cz.

Supported by the Internal Grant Agency of the Ministry of Health of the Czech Republic (grant NE/6430-5), the European Commission (LSHM-CT-2004-005272 and FOOD-CT-2005-007036) and the Barrande - Czech and French integrated program (2-06-32).

DOI: 10.1203/01.PDR.0000242301.64555.e2 linked to lipid metabolism $(7,10-14)$ and possibly also to production of reactive oxygen species (15) in skeletal muscle. Therefore, abnormal postnatal development of UCP3 might have severe metabolic consequences.

The reason for the impaired postnatal recruitment of UCP3 in very premature neonates has not been clarified (6). It could reflect activation of its promoter (16) by fatty acids (FA) via a transcription factor, the peroxisome proliferator-activated receptor $\alpha(17,18)$, as well as the control by MyoD, the regulator of differentiation program of muscle cells (19), or the control by thyroid hormones (20) (see also Discussion). AMP-activated protein kinase (AMPK) could also be involved. This enzyme is a sensor of cellular energy stress that, once phosphorylated due to an increase in the cellular AMP/ ATP ratio or other stimulus, activates ATP-producing processes while switching off ATP-consuming metabolic pathways (21). Activation of AMPK in skeletal muscle in response to contraction results in increased glucose uptake (22) and FA oxidation (23). Moreover, activation of AMPK in skeletal muscle by an adenosine analog (5-aminoimidazole-4carboxamide-1- $\beta$-D-ribofuranoside) increases expression of genes for GLUT4, and for mitochondrial proteins (24), including UCP3 (25-29). AMPK has also a role in the regulation of the transcription of genes involved in glucose and lipid metabolism in muscle during starvation (30). Importantly, upregulation of AMPK was shown to be responsible for increase of myocardial FA oxidation following birth in the rabbit (31). A homolog of mammalian AMPK, SNF1 protein kinase, is involved in the shift from anaerobic to aerobic metabolism in yeast (32).

This report represents an extension of our earlier study on the expression of UCP3 in skeletal muscle in premature

Abbreviations: AMPK, AMP-activated protein kinase; $\boldsymbol{\alpha} 2$-AMPK, $\alpha 2$-subunit of AMP-activated protein kinase; $\boldsymbol{\alpha} \mathbf{2}-\mathbf{K O}$, whole-body knockout of $\alpha 2$-subunit of AMP-activated protein kinase; EF-1 $\alpha$, elongation factor $1 \alpha$; FA, fatty acids; LCP, long-chain polyunsaturated fatty acids; qRT-PCR, real-time quantitative PCR; $\mathbf{T}_{\mathbf{3}}, 3,5,3^{\prime}$-triiodothyronine; UCP3, uncoupling protein 3 
neonates (33). Our unique experimental cohort was enlarged from 28 to 45 cases, mostly extremely low birth weight newborns who died as a result of various pathologic conditions associated with prematurity. The main goals of the present study were to: 1) to verify the striking observation (6) that the inducibility of the UCP3 gene by lipids in neonates depends on the gestational age at birth rather than on the postnatal (and postconceptional) age; and 2) assess a possible role for AMPK in the control of the UCP3 and GLUT4 gene expression in the developing muscle.

\section{METHODS}

Human material. Samples of musculus quadriceps femoris were obtained from human newborns who died during 1995-2004 $(n=40$, gestational age at birth: median $25 \mathrm{wk}$, range $22-39 \mathrm{wk}$; birth weight: median $700 \mathrm{~g}$, range $380-3210 \mathrm{~g}$ ). Samples were collected during autopsy $2-3 \mathrm{~h}$ after the death. In addition, 5 aborted fetuses (20-24 wk of gestation) were also examined (Table 1). Twenty-eight cases from this cohort (26 newborns and 2 fetuses were already included in our previous studies $(6,34,35)$ (Table 1). Most of the newborns had an extremely low birth weight $(<1000 \mathrm{~g}, 31$ cases, $78 \%$; Table 1). There were also 9 newborns with a birth weight $>1000 \mathrm{~g}$ (and gestational age $\geq 28$ wk). A majority of the newborns died during the first postnatal month (32 cases, $80 \%$; Table 1), the maximum length of survival was $140 \mathrm{~d}$ (Table 1). Nutritional and other clinical data were recorded (Table 1). Infants born from mothers, who suffered from endocrinological disorders or with drug abuse, were not eligible for the study. For isolation of total RNA and characterization of gene expression (see below), samples were either frozen and stored in liquid nitrogen (cases A31-A69, D14, Ab1, and Ab2), or they were preserved using RNAlater ${ }^{\mathrm{TM}}$ (Ambion, Austin, TX) and stored at $-70^{\circ} \mathrm{C}$ (cases A70 onwards). The study protocol conforms to the ethical guidelines of the 1975 Declaration of Helsinki, and it was approved a priori by the Committees of Medical Ethics at all the collaborating institutions. Informed consent was obtained from the parents.

Animals. WT and homozygous $\alpha 2$-AMPK whole-body knockout ( $\alpha 2$-KO) male mice, both strains on C57BL/6J background (36), were housed in a controlled environment $\left(20^{\circ} \mathrm{C}\right.$; 12 -h light-dark cycle; light from $\left.6: 00 \mathrm{~h}\right)$ with free access to water and standard chow diet. At the age of $3 \mathrm{mo}$, the mice were killed by cervical dislocation. Samples of musculus gastrocnemius and musculus soleus were dissected, flash-frozen and stored in liquid nitrogen

$\boldsymbol{R N A}$ analysis. Total RNA was isolated and levels of different transcripts were evaluated using real-time quantitative PCR (qRT-PCR) as before (6) with primers designed for human and mouse genes for UCP3, GLUT4, and $\alpha 2$ - subunit of AMPK ( $\alpha 2$-AMPK; Table 2$)$. Values for each transcript represent means of at least two independent measurements. To correct for intersample variation, concentrations of the UCP3, GLUT4, and $\alpha 2$-AMPK transcripts were normalized using elongation factor- $1 \alpha$ (EF- $1 \alpha$; human samples (6)) or cyclophilin (mouse samples) as housekeeping genes. When cases included in our previous studies were analyzed $(n=28$; Table 2$)$, new reverse transcription of the original RNA samples was performed. Strong correlation was found between UCP3 transcript levels estimated both previously (6) and in this study (Table 2) using linear regression analysis ( $\mathrm{r}=0.96, p<0.001$; all the cases lay within $99 \%$ confidence interval, except for A63, A71, and A76).

Statistics. Logarithmic transformation was used to stabilize variance when necessary. Spearman rank order correlation coefficient was used to evaluate the relationship between data, except for the linear regression analysis of UCP3 quantification above. Statistical significance of differences between groups was evaluated using Mann-Whitney U-Test or nonparametric Friedman test for one-way ANOVA model with post hoc tests using Wilcoxon matched-pairs test with Holm's adjustment of the significance level of individual comparisons. The level of significance of all tests was set at $p=$ 0.05 .

\section{RESULTS}

Gene expression in human muscle. Our previous characterization of UCP3 expression in musculus quadriceps femoris, containing both glycolytic and oxidative muscle fibers, of 26 preterm neonates and 2 fetuses (6) was extended to include 14 more neonates and 3 more fetuses. In addition to UCP3, expression of GLUT4 and $\alpha 2$-AMPK was also evaluated in all the samples using qRT-PCR. As before (6), the expression data were analyzed to reveal the effects of gestational age at birth and length of survival. Also the effect of lipids in nutrition received during the last $48 \mathrm{~h}$ before death was evaluated by comparing parenteral nutrition without any lipids (or absence of any nutrition) versus parenteral nutrition with lipids, or enteral nutrition.

Statistical analysis of the data (Table 3) confirmed the positive correlation between UCP3 expression and gestational age at birth, while no effect of the length of survival was found when all cases were analyzed together. The correlation between the expression and the gestational age was even stronger with lipids in nutrition, while no effect was found in the absence of nutritional lipids (or any nutrition; Table 3). No correlation between UCP3 transcript level and either the gestational age at birth or length of survival was found within subgroups with the gestational age below and above $25.5 \mathrm{wk}$, respectively, i.e. within subgroups differing largely in UCP3 expression (6) (Fig. 1). When GLUT4 and $\alpha 2$-AMPK expression were analyzed similarly as in the case of UCP3, a strong positive correlation was only found between GLUT4 expression and gestational age at birth with the neonates born later than at $25.5 \mathrm{wk}$ of gestation. No other correlations were detected (Table 3 ).

Plots of the level of the individual transcripts as a function of gestational age at birth (Fig. 1) confirmed the borderline of about $25.5 \mathrm{wk}$ (6) between subgroups differing substantially in $\mathrm{UCP} 3$ expression, and the stimulatory effect (3-fold; $p=0.02$ ) of nutritional lipids on the UCP3 expression in neonates born after 25.5 wk of gestation. No stimulation by lipids was detected in the neonates born at earlier stages of gestation. In the neonates born after $25.5 \mathrm{wk}$ of gestation, those fed enterally (A88, A91, and A92) tended to exhibit higher mean UCP3 transcript levels than neonates (A44, A63, A70, A75, A76) receiving parenteral nutrition with lipids $(10.1 \pm 1.5$ versus $6.8 \pm 2.0$ arbitrary units, means $\pm \mathrm{SE}$ ) but this difference was not statistically significant. In fact, the mean values of the UCP3 expression were several-fold higher in the group with age above 25.5 wk compared with the younger neonates/ aborted fetuses, and this difference was greater with than without lipids in nutrition (about 10- and 4-fold difference, respectively; Fig. 1). The plots of GLUT4 and $\alpha 2$-AMPK data document the lack of the effects of the length of gestation, and lipids, respectively, except for the effect of gestational age on GLUT4 expression in neonates born after $25.5 \mathrm{wk}$ of gestation (Fig. 1, compare with Table 3).

To reveal possible control of UCP3, GLUT4 genes by $\alpha 2$-AMPK, relations between individual transcripts were analyzed (Table 4). There was a weak but significant correlation between UCP3 and $\alpha 2$-AMPK transcript levels when all the cases were analyzed together and this correlation was stronger in neonates born after $25.5 \mathrm{wk}$ of gestation, provided that effect of nutritional lipids was not considered (Table 4). However, there was no correlation when all cases were subdivided using the presence of lipids in nutrition as a criterion (Table 4), or in deliveries before $25.5 \mathrm{wk}$ of gestation. The strongest correlation between the two transcripts was found in 
UCP3 AND AMPK IN HUMAN SKELETAL MUSCLE

Table 1. Cases examined and gene expression in skeletal muscle

\begin{tabular}{|c|c|c|c|c|c|c|c|c|c|c|c|}
\hline Case & Sex & $\begin{array}{l}\text { Gestational } \\
\text { age at birth } \\
\text { (wk)* }\end{array}$ & $\begin{array}{l}\text { Birth } \\
\text { weight } \\
\text { (g) }\end{array}$ & $\begin{array}{l}\text { Survival } \\
\text { (d) } * *\end{array}$ & \multicolumn{3}{|c|}{ Nutrition $\dagger$} & $\begin{array}{c}\text { Clinical diagnosis } \\
\text { and pathological } \\
\text { anatomy characteristics }\end{array}$ & \multicolumn{3}{|c|}{ Transcript levels $\ddagger$} \\
\hline A97\| & $\mathrm{F}$ & 20 & 350 & $0 \mathrm{~min}$ & & & & & 0.03 & 6.32 & 10.91 \\
\hline A100 & M & 22 & 510 & 4 & & & + & G, RDS, PDA, ICH & 0.95 & 23.60 & 8.90 \\
\hline A93 & M & 22 & 500 & 1.9 & & + & & $\mathrm{G}, \mathrm{TL}, \mathrm{ICH}, \mathrm{RDS}$ & 2.29 & 9.78 & 20.09 \\
\hline A94 & M & 23 & 450 & 11.6 & & & + & RDS, S, ICH, PHC, MOF, NEC & 2.55 & 7.75 & 14.43 \\
\hline A50§ & M & 23 & 550 & 8 & + & & + & $\mathrm{G}, \mathrm{ICH}, \mathrm{RDS}, \mathrm{S}, \mathrm{PDA}$ & 0.72 & 15.34 & 12.76 \\
\hline $\mathrm{A} 61 \S$ & M & 23 & 630 & 36 & & + & & CLD, HY, NEC, PDA, RF, RDS, S & 1.92 & 5.63 & 3.96 \\
\hline $\mathrm{A} 82 \S$ & M & 23 & 690 & 14 & & & + & RDS, PH, PDA, NEC, S, M & 0.61 & 5.32 & 0.72 \\
\hline A104\| & $\mathrm{F}$ & 24 & 530 & $\mathbf{0}$ min & & & & IA & 0.00 & 2.02 & 0.00 \\
\hline A67§ & $\mathrm{F}$ & 24 & 635 & 39 & & & + & G, ICH, NEC, PP, RDS, S & 0.68 & 5.27 & 4.41 \\
\hline A96 & M & 24 & 700 & 1.9 & & + & & $\mathrm{A}, \mathrm{TL}, \mathrm{RDS}, \mathrm{ICH}, \mathrm{HR}$ & 1.28 & 8.23 & 10.84 \\
\hline A102 & $\mathrm{F}$ & 24 & 610 & 20 & + & & + & T, RDS, PDA, ICH,S & 2.51 & 49.39 & 6.21 \\
\hline A71§ & M & 24 & 680 & 2 & & + & & $\mathrm{PPH}, \mathrm{P}, \mathrm{CHA}$ & 2.72 & 13.56 & 12.35 \\
\hline A79§ & M & 25 & 650 & 16 & & + & & $\mathrm{G}, \mathrm{S}, \mathrm{RDS}, \mathrm{NEC}, \mathrm{PDA}, \mathrm{MOF}$ & 0.17 & 2.91 & 1.20 \\
\hline A77§ & M & 25 & 690 & 4 & & + & & $\mathrm{ICH}, \mathrm{cPVL}$ & 0.29 & 17.22 & 10.41 \\
\hline $\mathrm{A} 78 \S$ & M & 25 & 750 & 20 & & & + & RDS, S, NEC, ICH, PHC, MOF & 0.13 & 1.78 & 2.18 \\
\hline A90 & M & 25 & 985 & 17.3 & + & & + & ICH,G,RDS, PIE, PH, PDA, S & 3.93 & 11.82 & 18.78 \\
\hline A84 & $\mathrm{F}$ & 25 & 630 & 19 & + & & + & EOI, ICH, RDS, PDA & 0.14 & 6.79 & 6.99 \\
\hline $\mathrm{A} 74 \S$ & $\mathrm{F}$ & 25 & 380 & 6 & & & + & SGA, PE, RDS, PDA, S, P, ICH & 0.74 & 15.29 & 31.67 \\
\hline D14§ & $\mathrm{F}$ & 25 & 730 & 5 & & + & & G, IA, ICH, NEC, RDS & 0.53 & 4.00 & 10.16 \\
\hline $\mathrm{A} 69 \S$ & $\mathrm{F}$ & 25 & 850 & 75 & & + & & PA, RDS, PNO, S, I CH, PVL, PDA, NEC, MOF & 0.07 & 8.53 & 37.27 \\
\hline $\mathrm{A} 73^{\S}$ & M & 25 & 435 & 69 & + & & & G, SGA, RDS, MOF, P, ICH, IUT-D & 0.16 & 7.02 & 5.92 \\
\hline $\mathrm{A} 80 \S$ & M & 25 & 700 & 3 & & & + & G, IUT-A, HK, RDS, ICH & 0.12 & 6.18 & 4.75 \\
\hline $\mathrm{A} 75 \S$ & M & 30 & 1295 & 10 & & & + & RDS, M & 11.82 & 14.50 & 19.52 \\
\hline A66§ & $\mathrm{F}$ & 31 & 1450 & 5 & & + & & HIE, IA & 0.11 & 2.01 & 3.73 \\
\hline A76§ & M & 32 & 750 & 7 & & & + & RDS, SGA, G, S, DS, MI & 1.63 & 5.19 & 9.01 \\
\hline A98 & M & 32 & 1840 & $9 \mathrm{~h}$ & & + & & LH, RDS & 2.39 & 26.07 & 18.34 \\
\hline A70§ & $\mathrm{F}$ & 35 & 1950 & 13 & & & + & PE, RDS, PIE, HK, PHC, MOF & 7.79 & 20.70 & 5.48 \\
\hline A 88 & $\mathrm{~F}$ & 36 & 1790 & 89.7 & + & & & $\mathrm{LH}, \mathrm{SGA}$ & 10.67 & 20.20 & 13.73 \\
\hline $\mathrm{A} 83 \S$ & M & 37 & 3210 & $4 \mathrm{~h}$ & & + & & LH, PIE, PNO, RF & 0.10 & 8.23 & 4.67 \\
\hline A103 & $\mathrm{F}$ & 39 & 1500 & $19 \mathrm{~h}$ & & + & & SGA, RDS, LH, PNO, HK & 10.74 & 25.97 & 27.24 \\
\hline
\end{tabular}

A, anemia; CHA, chorioamnionitis; CHT, chromosomal translocation 45/14q21q; CLD, chronic lung disease; cPVL, cystic periventricular leucomalatia; DIC, disseminated intravascular coagulation; DS, Down syndrome; EOI, early onset infection; G, gemini; HIE, hypoxic-ischemic encephalopathy; HK, hypertrophic cardiomyopathy; HR, hepatic rupture; HS, hemorrhagic shock; HY, severe hypothermia (body temperature $<31^{\circ} \mathrm{C}$ ) during the early postnatal period; IA, intrauterine asphyxia; ICH, intracranial hemorrhage; IUT-A, intrauterine transfusion acceptor; IUT-D, intrauterine transfusion donor; LH, lung hypoplasia; M, meningitis; MI, meconium ileus; MM, multiple malformations; MOF, multi-organ failure; NEC, necrotizing enterocolitis; P, pneumonia; PA, perinatal asphyxia; PDA, patent ductus arteriosus; PE, pre-eclampsia; PH, pulmonary hemorrhage; PHC, post-hemorrhagic hydrocephalus; PIE, pulmonary emphysema; PNO, pneumothorax; PP, peripheral pancytopenia; PPH, persistent pulmonary hypertension; RDS, respiratory distress syndrome; RF, respiratory failure; S, sepsis; SGA, small for gestational age; TGV, transposition of the great vessels; T, triplets; TL, traumatic labor.

* Cases were sorted according to gestational age at birth.

** In days, except when indicated otherwise (in bold type).

$\dagger$ Type of nutrition during the last $48 \mathrm{~h}$ before death: E, enteral nutrition (human milk or preterm formula); P, parenteral nutrition without lipids; PL, parenteral nutrition containing lipids (i.e. lipid emulsions containing both long- and medium-chain FA; the Lipofundin MCT/LCT 20\%, B. Braun Melsungen AG, Melsungen, Germany, or the Nutralipid MCT 20\% Emulsion, ICN Czech Republic, Prague).

$\ddagger$ Transcripts were quantified using qRT-PCR and expressed relative to that of EF- $1 \alpha$ (see Methods section).

$\S$ Cases examined in our previous studies $(6,34,35)$.

|l Abortion. 
Table 2. Sequences of PCR primers

\begin{tabular}{|c|c|c|c|}
\hline Gene & Sense primer $\left(5^{\prime}-3^{\prime}\right)$ & Antisense primer ( $\left.5^{\prime}-3^{\prime}\right)$ & $\begin{array}{c}\text { GeneBank } \\
\text { accession no. } \\
\text { for cDNA }\end{array}$ \\
\hline \multicolumn{4}{|l|}{ Human genes } \\
\hline $\mathrm{EF}-1 \alpha$ & GAACCATCCAGGCCAAATAAGC & CCACCGCAACTGTCTGTCTCATA & AY043301.1 \\
\hline UCP3* & AGAACCATCGCCAGGGAGGAAGGA & CACCGGGGAGGCCACCACTGT & XM_006360.1 \\
\hline GLUT4 & CCGTCGGGCTTCCAACAGATAGG & ACGGAAAAGATGGCCACGGAGAG & M20747.1 \\
\hline$\alpha 2-\mathrm{AMPK}$ & GTGGCGTCAAGGAATCCGAAGTCAG & GTAAGCCAGCAGCAGAACAGGAACG & NM_006252.1 \\
\hline \multicolumn{4}{|l|}{ Mouse genes } \\
\hline Cyclophilin & ACTACGGGCCTGGCTGGGTGAG & TGCCGGAGTCGACAATGATGA & M60456.1 \\
\hline $\mathrm{UCP} 3$ & Identical with human primers, see above & & \\
\hline GLUT4 & ACCGGCTGGGCTGATGTGTCT & GCCGACTCGAAGATGCTGGTTGAATAG & AB008453.1 \\
\hline$\alpha 2$-АMPK & AGCAGCTGGGTTTTGAATGGAAGGT & GGAGGCCCGCAGCAGAACAGG & $* *$ \\
\hline
\end{tabular}

* Primers detect both long and short forms of UCP3 transcript.

** Combination of XM_131633.3 and BF462177.1.

Table 3. Relations between the transcript levels in human skeletal muscle and gestational age or survival

\begin{tabular}{|c|c|c|c|c|c|}
\hline & \multirow{2}{*}{$\begin{array}{c}\text { All } \\
\text { cases }\end{array}$} & \multicolumn{2}{|c|}{$\begin{array}{l}\text { Gestational age } \\
\text { at birth }\end{array}$} & \multicolumn{2}{|c|}{ Nutrition } \\
\hline & & $<25.5$ wk & $>25.5 \mathrm{wk}$ & PA & $E+P L$ \\
\hline \multicolumn{6}{|c|}{ Gestational age at birth $v s$} \\
\hline UCP3 & $0.391^{* *}$ & $\quad-0.009$ & 0.103 & 0.409 & $0.526^{* *}$ \\
\hline GLUT4 & 0.210 & 0.180 & $0.534 * *$ & 0.322 & 0.040 \\
\hline$\alpha 2-$ AMPK & 0.062 & 0.076 & 0.362 & 0.021 & 0.077 \\
\hline \multicolumn{6}{|l|}{ Survival vs } \\
\hline $\mathrm{UCP} 3$ & 0.265 & 0.203 & 0.427 & 0.301 & -0.015 \\
\hline GLUT4 & 0.018 & -0.011 & -0.013 & -0.058 & -0.286 \\
\hline$\alpha 2$-AMPK & -0.112 & -0.089 & -0.185 & -0.090 & -0.318 \\
\hline$n$ & 45 & 23 & 22 & 17 & 28 \\
\hline
\end{tabular}

Transcripts were quantified using qRT-PCR and expressed relative to that of EF-1 $\alpha$ (Methods section) in cases described in Table 1. Spearman rank order correlation test was used to perform pair-wise comparison of gestation age at birth, or length of survival after birth, respectively, with transcript levels. $\mathrm{R}$ values are shown. Data were analyzed in all cases, or with respect to the type of nutrition during the last $48 \mathrm{~h}$ before death (parenteral nutrition without lipids, or absence of any nutrition (PA) vs enteral nutriton, or parenteral nutrition with lipids $(\mathrm{E}+\mathrm{PL})$ ), or with respect to the gestational age at birth.

$* * p<0.01$.

neonates born after $25.5 \mathrm{wk}$ of gestation and receiving lipids in nutrition, while a weaker and less significant correlation became apparent within this type of nutrition in the lower gestational age group. Without nutritional lipids, no correlation was found, regardless of the gestational age. These results are compatible with the involvement of AMPK on the control of the UCP3 gene, and especially in the induction of the UCP3 gene by lipids in neonates with the higher gestational age.

Since peroxisome proliferator-activated receptor $\alpha$, as well as MyoD, could be involved in the control of UCP3 gene [Introduction; (16-18)], transcripts of these genes were also quantified in majority of samples $(n=28)$. However, no association between any of these transcripts and that for UCP3 could be detected (not shown).

Correlation between GLUT4 and $\alpha 2$-AMPK transcripts was also detected. However, in contrast to the correlation between UCP3 and $\alpha 2$-AMPK transcripts, this correlation was found under all the situations analyzed, it was relatively strong and it was of a similar magnitude under all circumstances. Only in the neonates delivered after $25.5 \mathrm{wk}$ of gestation and subdi- vided according to the presence of lipids in their nutrition, the correlations lacked statistical significance. These results may be explained by involvement of AMPK in the control of the GLUT4 gene.

Gene expression in murine muscles. To understand the relationships detected between $\alpha 2$-AMPK and UCP3, and GLUT4, respectively, under the complex situation in human newborns (see above), gene expression was evaluated in skeletal muscles of adult WT mice with homogeneous genetic background and under standard laboratory conditions (Table 5). Thus, any possible confounding effect of any developmental regulatory factor(s) was eliminated. Expression of all three genes was measured in glycolytic (gastrocnemius) and oxidative (soleus) muscles. In both types of muscle, positive correlations between $\alpha 2$-AMPK and UCP3, and $\alpha 2$-AMPK and GLUT4, respectively, were found. The strength of these correlations was greater in the case of $\alpha 2$-AMPK and GLUT4 than in the case of $\alpha 2$-AMPK and UCP3 and it was not affected by the type of muscle.

The above results indicated correlations between transcripts for $\alpha 2$-AMPK and each of the two other genes, even in the absence of any developmental regulation. However, the correlations could not reveal a mechanistic link between transcripts. Therefore, in further experiments, expression of UCP3 and GLUT4 genes was quantified in WT and $\alpha 2-\mathrm{KO}$ mice (Table 6). The expression of both genes was similar under all the circumstances in both genotypes, except for UCP3 expression in the soleus muscle. In this case, UCP3 transcript levels were significantly (1.5-fold) lower in $\alpha 2$-KO compared with WT animals.

\section{DISCUSSION}

The present study documents further the vast difference with respect to the postnatal induction of UCP3 in skeletal muscle between very premature newborns and neonates delivered at later stages of gestation. At the gestational age lower than $25.5 \mathrm{wk}$, the expression of UCP3 is quite similar and relatively low, regardless of the presence of lipids in nutrition. This is in sharp contrast with the newborns delivered after a longer period of intrauterine development who exhibited a quite variable UCP3 expression, depending apparently on the induction of the UCP3 gene by lipids in their nutrition. Thus, 

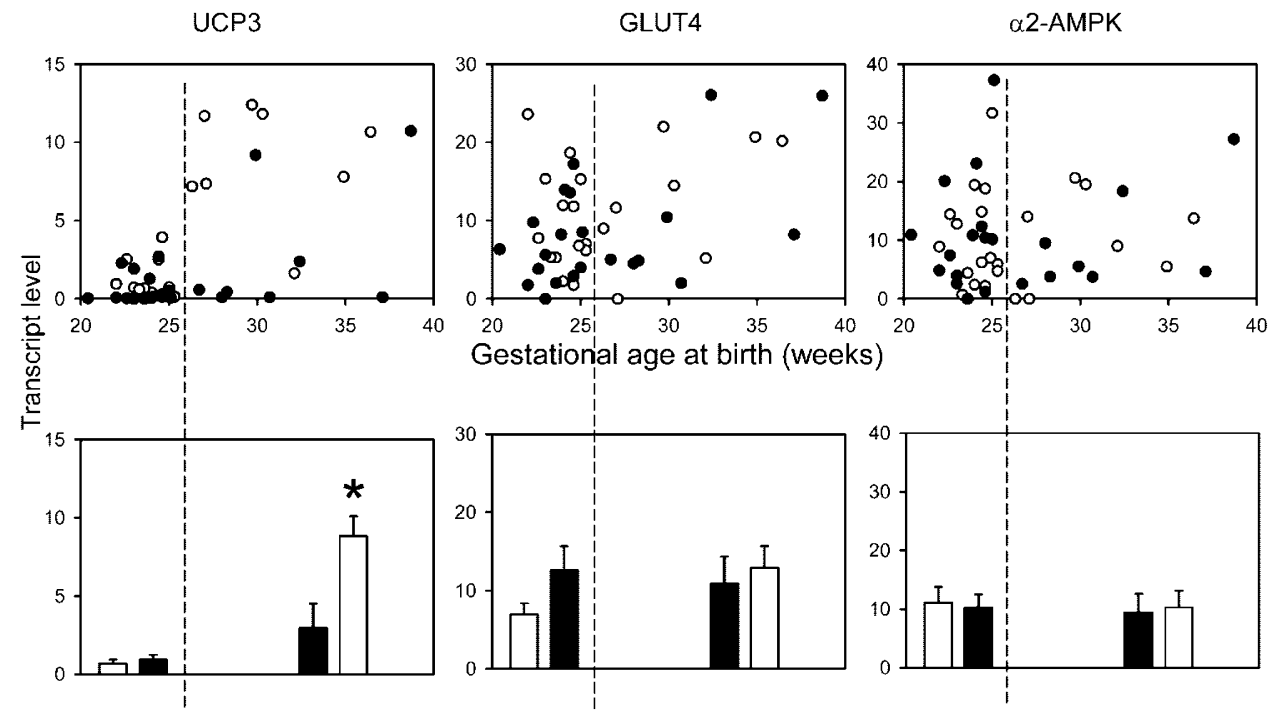

Figure 1. Expression of selected transcripts in human skeletal muscle. In the 45 cases described in Table 1, transcripts were quantified using qRT-PCR and expressed relative to that of EF-1 $\alpha$ (Methods section). Upper panels: gene expression plotted as a function of the length of gestation before birth/abortion for individual cases. Lower panels: mean values of transcript levels \pm SE plotted separately for gestational age at birth/abortion under and above 25.5 wk, respectively (dashed lines); for $n$ values, see Table 4. Open symbols and white bars, parenteral nutrition without lipids (or any nutrition); filled symbols and black bars, enteral nutrition, or parenteral nutrition with lipids during the last $48 \mathrm{~h}$ before death.

Table 4. Relations between transcript levels in human skeletal muscle

\begin{tabular}{|c|c|c|c|c|c|c|c|c|c|}
\hline & All cases & \multicolumn{2}{|c|}{ Gestational age at birth } & \multicolumn{2}{|c|}{ Nutrition } & \multicolumn{2}{|c|}{$<25.5$ wk } & \multicolumn{2}{|c|}{$>25.5 \mathrm{wk}$} \\
\hline UCP3 vs $\alpha 2$-AMPK & $0.324 *$ & 0.371 & $0.568 *$ & 0.346 & 0.346 & 0.369 & $0.529 *$ & 0.450 & $0.850 * *$ \\
\hline$n$ & 45 & 28 & 17 & 22 & 23 & 13 & 15 & 9 & 6 \\
\hline
\end{tabular}

Transcripts were quantified in the cases described in Tables 1 and 3. Spearman rank order correlation test was used to perform pair-wise comparison of transcript levels. R values are shown. Data were analyzed in all cases, or with respect to the type of nutrition during the last $48 \mathrm{~h}$ before death (parenteral nutrition without lipids, or absence of any nutrition (PA) vs enteral nutriton, or parenteral nutrition with lipids (E + PL)), or with respect to the gestational age at birth. Within the different age groups, further analysis was performed with respect to the type of nutrition.

$* p=0.01-0.05$.

$* * p<0.01$.

Table 5. Relations between transcript levels in murine skeletal muscles

\begin{tabular}{lcc}
\hline & Gastrocnemius & Soleus \\
\hline UCP3 vs $\alpha 2$-AMPK & $0.543^{* *}$ & $0.603^{* *}$ \\
GLUT4 s $\alpha 2$-AMPK & $0.920^{* *}$ & $0.836^{* *}$ \\
\hline
\end{tabular}

Transcripts were quantified using qRT-PCR and expressed relative to that of cyclophilin (Methods).Mean values \pm SE $(n=20)$ for UCP3, GLUT4 and $\alpha 2$-AMPK in gastrocnemius muscle were $2.45 \pm 0.32,4.23 \pm 0.26$, and $14.69 \pm 0.83$, respectively; corresponding values for soleusmuscle were 0.75 $\pm 0.07,3.12 \pm 0.21$, and $8.21 \pm 0.48$. All differences between the two muscles were statistically significant. Spearman rank order correlation test was used to perform pair-wise comparison of transcript levels. $\mathrm{R}$ values are shown.

$* p=0.01-0.05$.

$* * p<0.01$.

mean UCP3 transcript levels in neonates receiving lipids differs by one order of magnitude between the two groups separated by the length of the intrauterine development. It is striking that even within neonates receiving lipids in nutrition, those born between $24-25 \mathrm{wk}$ of gestation and surviving for a relatively long period (39-140 d; see cases A67 and A31 in Table 1) exhibited much lower UCP3 transcript levels than those with overlapping postconceptional age (31-44 versus
Table 6. Levels of UCP3 and GLUT4 transcripts in skeletal muscles of WT and $\alpha 2-K O$ mice

\begin{tabular}{lccccc}
\hline & \multicolumn{2}{c}{ Gastrocnemius } & & \multicolumn{2}{c}{ Soleus } \\
\cline { 2 - 3 } \cline { 5 - 6 } & WT & KO & & WT & KO \\
\hline UCP3 & $1.00 \pm 0.20$ & $0.81 \pm 0.10$ & & $0.77 \pm 0.05$ & $0.52 \pm 0.03 *$ \\
GLUT4 & $0.56 \pm 0.12$ & $0.57 \pm 0.06$ & & $0.41 \pm 0.03$ & $0.42 \pm 0.04$ \\
\hline
\end{tabular}

Transcripts were quantified using qRT-PCR and expressed relative to that of cyclophilin (Methods).

Values are means $\pm \operatorname{SE}(n=5)$.

* Significant difference between genotypes.

$30-32 \mathrm{wk}$ ) but born at later stages of gestation (at 26-30 wk; see cases A63, A92, A91, and A75 in Table 1). Thus, in agreement with the conclusion of our previous study (6) performed on a smaller number of cases $(n=28)$, the new analysis $(n=45)$ strongly suggests that the magnitude of the postnatal induction of UCP3 gene expression depends on the length of intrauterine development, and that appropriate conditions for the induction (by lipids) are not met by current clinical treatment of the very preterm newborns.

It may be speculated that pathologic conditions, which are of common occurrence in very preterm newborns, may affect gene expression in their muscle, like respiratory distress syn- 
drome, patent ductus arteriosus, or intrauterine asphyxia (Table 1). However, concerning complex health problems of all the critically ill newborns included in our study, possible effects of specific pathologic conditions are difficult to be dissected. We analyzed frequencies of individual clinical diagnosis in neonates below and above $25.5 \mathrm{wk}$ of the gestational age at birth, also with respect to the level of expression of the UCP3, GLUT4, and $\alpha 2$-AMPK genes. Using this approach, three pathologic conditions, i.e. necrotizing enterocolitis, sepsis, and multi-organ failure were found to be associated with relatively low expression of GLUT4, independently of the gestational age at birth. With two other diagnosis and transcripts, similar associations have not been observed (not shown).

UCP3 gene expression can be induced by thyroid hormones, especially by 3,5,3'-triiodothyronine $\left(\mathrm{T}_{3}\right)$ formed by deiodination of thyroxine in tissues (20). As also documented by our previous study (34), all preterm infants show transient hypopthyroxinemia during 6-8 wk of extrauterine life, rate of $\mathrm{T}_{3}$ formation in their muscle is relatively slow, and critically ill preterm infants have even lower plasma thyroid hormones levels than well being infants of similar age (euthyroid sick syndrome; low $\mathrm{T}_{3}$ syndrome). Therefore, thyroid-dependent regulation of UCP3 gene may be impaired in preterm infants. Further studies are required in this respect.

Statistical analysis of the present data revealed a correlation between transcripts for $\alpha 2$-AMPK and each of the two metabolic genes, UCP3 and GLUT4, in skeletal muscle of human fetuses and newborns. Experiments in adult WT mice confirmed these relationships, even in the absence of any developmental or nutritional stimuli which could orchestrate gene expression. Under both situations AMPK appeared to be more clearly associated to GLUT4 than to UCP3. Concerning the well-established regulatory role for AMPK in the transcriptional control of both UCP3 and GLUT4 (Introduction), the observed relationships are not unexpected. However, they represent novel findings, both in human fetuses and newborns, as well as in the adult mice. Furthermore, the experiments on the $\alpha 2-\mathrm{KO}$ mice support the involvement of AMPK in the control UCP3 gene expression, at least in the oxidative type of skeletal muscle. That genetic disruption of AMPK could decrease UCP3 transcript levels in the skeletal muscle at rest was not shown so far $(29,30)$. All these results support the role of AMPK in the postnatal activation of lipid oxidation in myocytes, both in the myocardium (31) and in skeletal muscle. Provided that UCP3 is linked to FA oxidation in muscle mitochondria, and that expression of its gene is much higher in the skeletal muscle than in the heart of human neonates (6), control of UCP3 gene by AMPK may be important for the postnatal switch between glycolytic and oxidative metabolism. However, the relationship between AMPK and UCP3 during postnatal development is based only on indirect evidence, reflecting inherent limitations of human studies. Relative importance of AMPK and other mechanisms engaged in control of UCP3 gene under these conditions remains to be established.

Further studies are required to elucidate the mechanism of the impaired induction of UCP3 gene expression by nutri- tional lipids in very premature neonates. It is also necessary to understand whether this defect is reflected by altered levels of UCP3 later in life and whether it has lasting metabolic consequences. In mice (17) and in humans (Results), lipids contained in both parenteral nutrition and milk could induce UCP3 gene expression. However, the FA specificity for this induction remains to be characterized. In adult rodents, the UCP3 gene is strongly induced by long-chain polyunsaturated FA (LCP) of n-3 family (37). Interestingly, LCP represent essential component of human milk and have numerous beneficial and lasting effects in breast-fed neonates $(38,39)$. Therefore, especially formulas for preterm neonates are being supplemented with LCP but the optimum dose and composition of LCP is difficult to assess (40). Breast-feeding is associated with a lower risk of development of both obesity (41) and type 2 diabetes (42) in childhood. It has been also demonstrated recently that children who were born prematurely show a reduction in insulin sensitivity (43). Impaired UCP3 gene expression may contribute to insulin resistance of these children, if it results in impaired FA oxidation and hence increased lipid accumulation in the muscle (44). Low UCP3 content has been found in muscles of diabetic patients (45).

In conclusion, our results indicate impaired postnatal activation by nutritional lipids of the UCP3 gene in skeletal muscle of very prematurely born neonates. They also suggest that besides other factors, AMPK is involved in the postnatal activation of the UCP3 gene. Further studies are required to elucidate possible causes and consequences of the defective recruitment of the UCP3 gene.

Acknowledgments. The authors thank to Prof. Arnost Kotyk for critical reading of the manuscript, and Jaroslava Bemova, Sona Hornova, and Daniela Salkova for technical assistance.

\section{REFERENCES}

1. Izquierdo JM, Luis AM, Cuezva JM 1990 Postnatal mitochondrial differentiation in rat liver. J Biol Chem 265:9090-9097

2. Schonfeld P, Schild L, Bohnensack R 1996 Expression of the ADP/ATP carrier and expansion of the mitochondrial (ATP + ADP) pool contribute to postnatal maturation of the rat heart. Eur J Biochem 241:895-900

3. Schagger H, Noack H, Halangk W, Brandt U, Von Jagow G 1995 Cytochrome-c oxidase in developing rat heart. Enzymic properties and amino-terminal sequences suggest identity of the fetal heart and the adult liver isoform. Eur J Biochem 230:235-241

4. Valcarce C, Izquierdo JM, Chamorro M, Cuezva JM 1994 Mammalian adaptation to extrauterine environment: mitochondrial functional impairment caused by prematurity. Biochem J 303:855-862

5. Sperl W, Sengers RC, Trijbels JM, Ruitenbeek W, Doesburg WH, Smeitink JA, Kollee LA, Boon JM 1992 Enzyme activities of the mitochondrial energy generating system in skeletal muscle tissue of preterm and fullterm neonates. Ann Clin Biochem 29:638-645

6. Brauner P, Kopecky P, Flachs P, Ruffer J, Sebron V, Plavka R, Vitkova I, Vorlicek J, Kopecky J 2003 Induction of uncoupling protein 3 gene expression in skeletal muscle of preterm newborns. Pediatr Res 53:691-697

7. Weigle DS, Selfridge LE, Schwartz MW, Seeley RJ, Cummings DE, Havel PJ, Kuijper JL, BeltrandelRio H 1998 Elevated free fatty acids induce uncoupling protein 3 expression in muscle: a potential explanation for the effect of fasting. Diabetes 47:298-302

8. Brun S, Carmona MC, Mampel T, Vinas O, Giralt M, Iglesias R, Villarroya F 1999 Uncoupling protein-3 gene expression in skeletal muscle during development is regulated by nutritional factors that alter circulating non-esterified fatty acids. FEBS Lett 453:205-209

9. Cline GW, Vidal-Puig AJ, Dufour S, Cadman KS, Lowell BB, Shulman GI 2001 In vivo effects of uncoupling protein-3 gene disruption on mitochondrial energy metabolism. J Biol Chem 276:20240-20244 
10. Samec S, Seydoux J, Dulloo AG 1998 Role of UCP homologues in skeletal muscles and brown adipose tissue: mediators of thermogenesis or regulators of lipids as fuel substrates? FASEB J 12:715-724

11. Garcia-Martinez C, Sibille B, Solanes G, Darimont C, Mace K, Villarroya F, Gomez-Foix AM 2001 Overexpression of UCP3 in cultured human muscle lowers mitochondrial membrane potential, raises ATP/ADP ratio, and favors fatty acid versus glucose oxidation. FASEB J 15:2033-2035

12. Himms-Hagen J, Harper ME 2001 Physiological role of UCP3 may be export of fatty acids from mitochondria when fatty acid oxidation predominates: an hypothesis. Exp Biol Med (Maywood) 226:78-84

13. Cadenas S, Buckingham JA, Samec S, Seydoux J, Din N, Dulloo AG, Brand MD 1999 UCP2 and UCP3 rise in starved rat skeletal muscle but mitochondrial proton conductance is unchanged. FEBS Lett 462:257-260

14. Clapham JC, Coulthard VH, Moore GB 2001 Concordant mRNA expression of UCP-3, but not UCP-2, with mitochondrial thioesterase-1 in brown adipose tissue and skeletal muscle in $\mathrm{db} / \mathrm{db}$ diabetic mice. Biochem Biophys Res Commun 287:1058-1062

15. Echtay KS, Roussel D, St Pierre, J Jekabsons MB, Cadenas S, Stuart JA, Harper JA, Roebuck SJ, Morrison A, Pickering S, Clapham JC, Brand MD 2002 Superoxide activates mitochondrial uncoupling proteins. Nature 415:96-99

16. Esterbauer H, Oberkofler H, Krempler F, Strosberg AD, Patsch W 2000 The uncoupling protein-3 gene is transcribed from tissue-specific promoters in humans but not in rodents. J Biol Chem 275:36394-36399

17. Brun S, Carmona MC, Mampel T, Vinas O, Giralt M, Iglesias R, Villarroya F 1999 Activators of peroxisome proliferator-activated receptor-a induce the expression of the uncoupling protein-3 gene in skeletal muscle. Diabetes 48:1217-1222

18. Young ME, Patil S, Ying J, Depre C, Ahuja HS, Shipley GL, Stepkowski SM, Davies PJ, Taegtmeyer H 2001 Uncoupling protein 3 transcription is regulated by peroxisome proliferator-activated receptor (alpha) in the adult rodent heart. FASEB J 15:833-845

19. Solanes G, Pedraza N, Iglesias R, Giralt M, Villarroya F 2000 The human uncoupling protein-3 gene promoter requires $\mathrm{MyoD}$ and is induced by retinoic acid in muscle cells. FASEB J 14:2141-2143

20. Gong DW, He Y, Karas M, Reitman M 1997 Uncoupling protein-3 is a mediator of thermogenesis regulated by thyroid hormone, beta3-adrenergic agonists, and leptin. J Biol Chem 272:24129-24132

21. Hardie DG 2004 The AMP-activated protein kinase pathway - new players upstream and downstream. J Cell Sci 117:5479-5487

22. Hayashi T, Hirshman MF, Kurth EJ, Winder WW, Goodyear LJ 1998 Evidence for 5' AMP-activated protein kinase mediation of the effect of muscle contraction on glucose transport. Diabetes 47:1369-1373

23. Winder WW, Hardie DG 1996 Inactivation of acetyl-CoA carboxylase and activation of AMP-activated protein kinase in muscle during exercise. Am J Physiol 270:E299-E304

24. Winder WW, Holmes BF, Rubink DS, Jensen EB, Chen M, Holloszy JO 2000 Activation of AMP-activated protein kinase increases mitochondrial enzymes in skeletal muscle. J Appl Physiol 88:2219-2226

25. Zhou M, Lin BZ, Coughlin S, Vallega G, Pilch PF 2000 UCP-3 expression in skeletal muscle: effects of exercise, hypoxia, and AMP-activated protein kinase. Am J Physiol Endocrinol Metab 279:E622-E629

26. Pedersen SB, Lund S, Buhl ES, Richelsen B 2001 Insulin and contraction directly stimulate UCP2 and UCP3 mRNA expression in rat skeletal muscle in vitro. Biochem Biophys Res Commun 283:19-25

27. Stoppani J, Hildebrandt AL, Sakamoto K, Cameron-Smith D, Goodyear LJ, Neufer PD 2002 AMP-activated protein kinase activates transcription of the UCP3 and HKII genes in rat skeletal muscle. Am J Physiol Endocrinol Metab 283:E1239-E1248

28. Suwa M, Nakano H, Kumagai S 2003 Effects of chronic AICAR treatment on fiber composition, enzyme activity, UCP3, and PGC-1 in rat muscles. J Appl Physiol 95:960-968
29. Jorgensen SB, Wojtaszewski JF, Viollet B, Andreelli F, Birk JB, Hellsten Y, Schjerling P, Vaulont S, Neufer PD, Richter EA, Pilegaard H 2005 Effects of alpha-AMPK knockout on exercise-induced gene activation in mouse skeletal muscle. FASEB J 19:1146-1148

30. Long YC, Barnes BR, Mahlapuu M, Steiler TL, Martinsson S, Leng Y, WallbergHenriksson H, Andersson L, Zierath JR 2005 Role of AMP-activated protein kinase in the coordinated expression of genes controlling glucose and lipid metabolism in mouse white skeletal muscle. Diabetologia 48:2354-2364

31. Makinde AO, Gamble J, Lopaschuk GD 1997 Upregulation of 5'-AMP-activated protein kinase is responsible for the increase in myocardial fatty acid oxidation rates following birth in the newborn rabbit. Circ Res 80:482-489

32. Hardie DG, Carling D, Carlson M 1998 The AMP-activated/SNF1 protein kinase subfamily: metabolic sensors of the eukaryotic cell? Annu Rev Biochem 67:821855

33. Martin JC, Niyongabo T, Moreau L, Antoine JM, Lanson M, Berger C, Lamisse F, Bougnoux P, Couet C 1991 Essential fatty acid composition of human colostrum triglycerides: its relationship with adipose tissue composition. Am J Clin Nutr 54:829-835

34. Pavelka S, Kopecky P, Bendlova B, Stolba P, Vitkova I, Vobruba V, Plavka R, Houstek J, Kopecky J 1997 Tissue metabolism and plasma levels of thyroid hormones in critically ill very premature infants. Pediatr Res 42:812-818

35. Brauner P, Nibbelink M, Flachs P, Vitkova I, Kopecky P, Mertelikova I, Janderova L, Penicaud L, Casteilla L, Plavka R, Kopecky J 2001 Fast decline of hematopoiesis and uncoupling protein 2 content in human liver after birth: location of the protein in Kupffer cells. Pediatr Res 49:440-447

36. Viollet B, Andreelli F, Jorgensen SB, Perrin C, Geloen A, Flamez D, Mu J, Lenzner C, Baud O, Bennoun M, Gomas E, Nicolas G, Wojtaszewski JF, Kahn A, Carling D, Schuit FC, Birnbaum MJ, Richter EA, Burcelin R, Vaulont S 2003 The AMPactivated protein kinase alpha2 catalytic subunit controls whole-body insulin sensitivity. J Clin Invest 111:91-98

37. Baillie RA, Takada RA, Nakamura M, Clarke SD 1999 Coordinate induction of peroxisomal acyl-CoA oxidase and UCP-3 by dietary fish oil: a mechanism for decreased body fat deposition. Prostaglandins Leukot Essent Fatty Acids 60:351356

38. Herrera E, Amusquivar E 2000 Lipid metabolism in the fetus and the newborn Diabetes Metab Res Rev 16:202-210

39. Bateson P, Barker D, Clutton-Brock T, Deb D, D'Udine B, Foley RA, Gluckman P, Godfrey K, Kirkwood T, Lahr MM, McNamara J, Metcalfe NB, Monaghan P, Spencer HG, Sultan SE 2004 Developmental plasticity and human health. Nature 430:419-421

40. Rodriquez- Palmero M, Koletzko B, Kunz C, Jensen R 1999 Nutritional and biochemical properties of human mikl: II Lipids, micronutrients, and bioactive factors. Clin Perinatol 26:335-359

41. Arenz S, Ruckerl R, Koletzko B, Von Kries R 2004 Breast-feeding and childhood obesity - a systematic review. Int J Obes Relat Metab Disord 28:1247-1256

42. Young TK, Martens PJ, Taback SP, Sellers EA, Dean HJ, Cheang M, Flett B 2002 Type 2 diabetes mellitus in children: prenatal and early infancy risk factors among Native Canadians. Arch Pediatr Adolesc Med 156:651-655

43. Hofman PL, Regan F, Jackson WE, Jefferies C, Knight DB, Robinson EM, Cutfield WS 2004 Premature birth and later insulin resistance. N Engl J Med 351:2179-2186

44. Petersen KF, Befroy D, Dufour S, Dziura J, Ariyan C, Rothman DL, DiPietro L, Cline GW, Shulman GI 2003 Mitochondrial dysfunction in the elderly: possible role in insulin resistance. Science 300:1140-1142

45. Schrauwen P, Hesselink MK, Blaak EE, Borghouts LB, Schaart G, Saris WH, Keizer HA 2001 Uncoupling protein 3 content is decreased in skeletal muscle of patients with type 2 diabetes. Diabetes 50:2870-2873 